\title{
Spectrophotometric Determination of Curcumin after Preconcentration by Ultrasonic Assisted Supramolecular Dispersive Liquid-liquid Microextraction based on Solidification of Floating Organic Drops using Taguchi Design Method
}

\author{
Ardeshir Shokrollahi*, (iD, Samira Hesampour
}

In this paper, the Taguchi orthogonal design was applied to optimize the extraction efficiencies for the determination of curcumin, after the separation and preconcenteration by supramolecular based-ultrasonic assisted-dispersion solidification liquid-liquid microextraction (SM-UA-DSLLME) procedure coupled with spectrophotometric UV-Vis. The experimental design consisted of six parameters $(\mathrm{pH}$, amount of the extraction and disperser solvents, salt effect, sonication time and centrifuge time), each at five levels. The preconcentration method is based on the dispersionsolidification liquid-liquid microextraction of curcumin with decanoic acid/THF as the supramolecular solvent (a nano-structured liquid occurring on two scales, molecular and nano). The purpose method had two linear ranges of $0.01-0.40$ and $0.40-3.50 \mathrm{mg} \mathrm{L}^{-1}$ of curcumin with $R^{2}=$ 0.9922 and 0.9799 , respectively. The enrichment factors of 478.48 and 118.80 were obtained for down and up linear ranges, respectively. The preconcentration factor under consideration recovery was obtained 46. Detection limit was $5.2 \mu \mathrm{g} \mathrm{L}^{-1}$ and the relative standard deviation (RSD\%), for eight replicate measurements of $0.2 \mathrm{mg} \mathrm{L}^{-1}$ curcumin was $2.47 \%$. The results obtained from the analysis of variance (ANOVA), revealed that the most important effectible parameters on extraction curcumin are volume of disperser solvent and $\mathrm{pH}$. The applicability of method was successfully applied to determine of trace curcumin in tablet, sewage and water samples.

\section{Introduction}

Curcumin (1,7-bis(4-hydroxy-3-methoxyphenyl) hepta1,6-diene-3,5-dione) is a yellow-orange crystalline powder and the principle compound of turmeric [1]. Curcumin is belonging to the ginger family native and is used extensively in the traditional medicine of various Asian countries. It has been used in various food processing industries due to its bright yellow color and in some countries, curcumin as an additive is permitted to be used in food [2]. The solubility of curcumin in organic solvents is very high but insoluble in aqueous solution and is unstable to light [3]. Numerous studies have reported that curcumin that due to its high capacity in interaction with different molecules used for the prevention and treatment of various malignant diseases such as cancer, diabetes, allergies and other chronic illnesses, due to its antiinflammatory, antioxidant, anticarcinogenic, antifungal,

Department of Chemistry, Yasouj University, Yasouj, Iran

${ }^{*}$ Corresponding author:

E-mail: ashokrollahi@mail.yu.ac.ir

Tel: +9874-32223048 Fax: +98743-2242147

DOI: 10.5185/amlett.2021.21111680 antiviral, antitumor [4]. In addition, this compound operates as potent scavenger of different reactive oxygen species, including superoxide anions and hydroxyl radicals. Many of these properties appear to be related to their carbonyl groups. Hence, it is important to develop cheap and effective analytical methods for the determination of the amount of curcumin in foodstuffs entering the human body. Several techniques have been used for the separation of curcumin from different samples, such as liquid-liquid extraction, sonication, soxhlet extraction [5], Microwaveassisted extraction (MAE) [6], Pressurized hot water extraction (PHWE), Supercritical fluid extraction (SFE) [7] and High-performance liquid chromatography (HPLC) [8]. Since curcumin concentration is too low to be determined directly, microextraction techniques have been gaining a growing interest in recent years, which reduces the amount of toxic organic solvents, time and cost and provides high enrichment factors [9]. Dispersive liquid-liquid microextraction (DLLME) that introduced by Assadi and co-workers [10], has been developed as an alternative to the classic liquid-liquid extraction. In this method, fine droplets of an extraction solvent are dispersed into an aqueous phase by the aim of polar solvent as disperser. In the last decade, many different DLLME methods, have been used for determination of curcumin including vortex assisted 
dispersive liquid-liquid microextraction [11], DLLME based on solidification of floating organic drop (DLLMESFO) [12], ultrasound-assisted ionic liquid-dispersive liquid-liquid microextraction method (UA-IL-DLLME) [13], and air assisted-dispersive liquid-liquid microextraction (AA-DLLME) [14,15], have been developed. DLLME-SFO is a good preconcentration procedure for extraction of metal ions [16], addective materials [17], herbicides [18] and food dyes [19]. In this technique, a trace amount of organic droplets can be easily conglomerated by solidifying it in the ice bath.

Although recently, deep eutectic solventemulsification liquid-liquid micro-extraction (VA-DESELLME) [20], ultrasound-assisted ionic liquid-dispersive liquid- liquid micro-extraction [13] and environmentresponsive long chain acid (C7-C14)- based supramolecular solvents (SUPRAs) [21] have begun to attract interest but still methods based on the application of supramolecular solvents constitute an environment friendly alternative to molecular organic ones for analytical extractions has attracted much research attention [22].

Supramolecular solvents are water-immiscible liquids made up of supramolecular parliament diffused in a continuous phase. They are organized from amphiphile solutions by a serial self-assembly happening on the molecular and nano-scales by the action of a coacervating agent (e.g. temperature, $\mathrm{pH}$, electrolyte, solvent) [23-26]. Pe'rez-Bendito et. al., offered supramolecular solvent made up of reverse micelles of decanoic acid (DeA) dispersed in tetrahydrofuran (THF)-water [27]. The method is environmentally friendly and is a good preconcentration procedure with advantages including inexpensive, high recovery, simple, low consumption, toxicity, density and high melting point of organic solvent, very short extraction time due to the very large surface area between the organic and aqueous phases [28-30].

Traditional optimization involves a large number of experiments, which can be costly and time consuming. In recent years, the Taguchi method is a systematic application of analysis of experiments for the of designing and improving product quality. It is used especially for appraising several process factors at a time with the smallest number of experimental runs based on a table, known as the orthogonal array. Taguchi design method become a powerful tool employed in industry for improving productivity and development, such as high-quality products can be produced quickly and low cost [31].

SM-UA-DSLLME can be a good method for the determination of curcumin because it has the advantages of simplicity; low cost, rapidity, simple apparatus and consumption of very small amount of low-toxic organic solvent.

The objective of the present study was to apply the Taguchi method to determine the optimum preconcentration and determination conditions for producing a high yield of curcumin by SM-UA-DSLLME method combined with spectrophotometry UV-Vis.

\section{Experimental}

\section{Apparatus}

The $\mathrm{pH}$ measurements were carried out by a Metrohm $\mathrm{pH}$ meter (model 827) with a combined glass calomel electrode. An ultrasonic bath with heating system (TecnoGAZ SPA UltraSonic System, Italy) at $40 \mathrm{kHz}$ of frequency and $130 \mathrm{~W}$ of power was used for the ultrasound-assisted extraction procedure. Centrifuge, Universal model (Iran) was used for the accelerate separation phases. A Biohit proline pipettor $100-1000 \mu \mathrm{L}$ was used for injecting samples into the microcells. PG Instruments Ltd T80+ (Japan) UV/Vis spectrometer was used for recording absorbance spectra that equipped with quartz tubes and quartz microplastics.

\section{Materials}

All chemicals used in this study were of analytical grade or higher purity. In addition, double distilled water was used for making all solutions. Decanoic acid (DeA), tetrahydrofuran (THF), ethanol, 1-dodecanol, methanol, acetone were purchased from Merck. Curcumin was purchased from Sigma Aldrich company. A stock solution of $50 \mathrm{mg} \mathrm{L}^{-1}$ of curcumin was prepared and the more diluted solution was prepared from it. Nitrate salts of cadmium, cobalt, nickel, copper, zinc, calcium, magnesium and other salts from Merck were of the highest purity available and used without any further purification. The rich phase was diluted with ethanol.

\section{SM-UA-DSLLME procedure}

For the SM-UA-DSLLME, the following procedure after optimization of effective parameters by Taguchi method was done: $10 \mathrm{~mL}$ sample solution containing $0.2 \mathrm{mg} \mathrm{L}^{-1}$ curcumin and $0.03 \mathrm{~mol} \mathrm{~L}^{-1}$ potassium chloride, then $\mathrm{pH}$ was adjusted at 1.5 by the addition of hydrochloric acid or sodium hydroxide. A solution of $51 \mathrm{mg}$ decanoic acid (extraction solvent) in $0.6 \mathrm{~mL}$ THF (disperser solvent) was injected rapidly into the solution using a $1.0 \mathrm{~mL}$ syringe. The mixture was kept in an ultrasonic bath for 1 minutes. In this stage, a cloudy solution was formed in the centrifuge tube, which was stable for a long course, and the supramolecular solvent spontaneously formed into the bulk solution. Then, the mixture was centrifuged for $10 \mathrm{~min}$ and a two-phase solution was acquired. Because of difference the density between the aqueous phase and supramolecular solvent, the fine droplets of supramolecular solvent float at the top of the centrifuge tube. After this process, the centrifuge tube was transferred into a bath containing the crushed ice for cooling. After $5 \mathrm{~min}$, the solidified solvent was transferred into a conical vial using simple spatula, and was diluted to $200 \mu \mathrm{L}$ with ethanol. Absorbance of the curcumin was measured at $\lambda_{\max }=425 \mathrm{~nm}$ against blank.

\section{Sample preparation}

(a) Tablet samples: The sample of curcuma tablet was prepared from the Dineh Pharmaceutical Company 
(Tehran, Iran). First, four tablets were finely grounded and mixed. One fourth of the tablet was dissolved with ethanol in $25 \mathrm{~mL}$ balloons and was delivered to volume. Then $1.0 \mathrm{~mL}$ of tablet was poured into a 250 $\mathrm{mL}$ balloon and was delivered to volume with distilled twice water. Then analyzed by the recommended procedure.

(b) Water samples: Two water samples, including tap water from our lab (Yasouj university, Iran) and kitchen sewage during the consumption turmeric were collected in polyethylene bottle. Each water sample was filtered, in order to remove any suspended material then analyzed by the recommended procedure.

\section{Result and discussion}

\section{Selection of extraction and disperser solvents}

The selection of appropriate extraction and disperser solvents are of great importance for the optimization of the DLLME-SFO process. The extraction solvent used for DLLME-SFO should have suitable physicochemical properties such as: low toxicity, low volatility, low melting point near room temperature (in the range of $10-30{ }^{\circ} \mathrm{C}$ ), lower density than water and low solubility in water. Additionally, it must be able to extract analytes well and also be suitable with the analytical technique of measurement. Furthermore, the most important point for the selection of the dispersive solvent is miscibility of disperser solvent with extraction solvent and aqueous phase, its toxicity and cost and could form a cloudy state when injected with the extractant into water [32]. Considering these requirements, several couples of extraction and disperser solvents such as 1undecanol/acetone [33], 1-dodecanol/methanol [34], 1dodecanol/acetone [35]. Hexadecane /acetonitrile [36] and decanoic acid /THF (DeA /THF) [16] have been studied, previously. In this work, three couples, i.e., 1-dodecanol /methanol, 1-dodecanol /acetone, and DeA/THF were examined in the extraction of curcumin. Consequently, the couple of DeA /THF was choiced for the extraction and preconcentration of curcumin. The couple of DeA/THF are the most appropriate system for analytical applications that can made up of reversed micelles [32] and THF plays double pattern, not only acts as disperser solvent but also causes self-assembly of DeA.

\section{Optimization of SM-UA-DSLLME}

The extraction performance of SM-UA-DSLLME procedure depends on some important experimental variables, which should be investigated in detail. The effects of sample $\mathrm{pH}$, amount of extraction and disperser solvents, effect of the salt addition, sonication and centrifuge times on the extraction of curcumin were investigated using Taguchi method. The Taguchi method can provide an effective experimental design, reduce the volume of calculations and use the $\mathrm{S} / \mathrm{N}$ ratio to measure the variations of the experimental results.

\section{Taguchi method}

Taguchi experimental design is mainly used to achieve high quality for determination of curcumin and effectively reduces the number of experimental trials. The control factors shown in Table 1, include different kinds and levels of $\mathrm{pH}$, amount of the extraction solvent, volume of disperser solvent, salt effect, ultrasonic time and sonication time. $\mathrm{L}_{25}\left(6^{5}\right)$ orthogonal arrays were selected for the experiments, and there were 25 experimental runs with 6 factors (columns) and 5 levels (rows). The data obtained from determination of curcumin was subjected to signal-to-noise $(\mathrm{S} / \mathrm{N})$ ratio calculation. The $\mathrm{S} / \mathrm{N}$ ratio calculation is an evaluation of output performance stability, and a high $\mathrm{S} / \mathrm{N}$ ratio value is used as an indicator of optimal conditions [37]. In this study, target values of 'larger is better' was used since the purpose of this study was to obtain the highest determination of curcumin. The $\mathrm{S} / \mathrm{N}$ ratio is calculated using the following. Equation (1):

$$
\frac{S}{N}=-10 \log \left(\frac{1}{n} \sum_{i=1}^{n} y_{i}^{2}\right)
$$

where $n$ is the number of trials in experiments, $i$ is the experiment number and $y$ is the response.

Table1. Factors and levels for the Taguchi $\mathrm{L}_{25}$ orthogonal design.

\begin{tabular}{lcccccc}
\hline \multicolumn{1}{c}{ Factor } & Unit & $\begin{array}{c}\text { Level } \\
\mathbf{1}\end{array}$ & $\begin{array}{c}\text { Level } \\
\mathbf{2}\end{array}$ & $\begin{array}{c}\text { Level } \\
\mathbf{3}\end{array}$ & $\begin{array}{c}\text { Level } \\
\mathbf{4}\end{array}$ & $\begin{array}{c}\text { Level } \\
\mathbf{5}\end{array}$ \\
\hline $\mathrm{pH}$ & - & 1 & 1.5 & 2 & 3 & 4 \\
$\begin{array}{l}\text { Amount of the } \\
\text { extraction solvent }\end{array}$ & $\mathrm{mg}$ & 21 & 31 & 41 & 51 & 61 \\
$\begin{array}{l}\text { Volume of } \\
\text { disperser solvent }\end{array}$ & $\mu 1$ & 100 & 300 & 400 & 500 & 600 \\
$\begin{array}{l}\text { Salt effect } \\
\text { Sonication time }\end{array}$ & $\mathrm{mol} \mathrm{L} \mathrm{L}^{-1}$ & 0 & 0.03 & 0.05 & 0.06 & 0.08 \\
Centrifuge time & $\mathrm{min}$ & 2 & 0.5 & 1 & 1.5 & 2 \\
\hline
\end{tabular}

The $\mathrm{S} / \mathrm{N}$ ratio calculation results for determination of curcumin are shown in Table 2 and Fig. 1. Analysis of variance (ANOVA) was adopted to investigate the significance of the influence and confidence of the processing parameters on the performance $[38,39]$. ANOVA is a statistical method that can determine the percentage and contribution of each controllable factor on percentage extraction of curcumin. This test was not employed for centrifuge time (with the least impact) due to the inability of ANOVA test in this software for the analysis of six parameters simultaneously. Summary results of the ANOVA are shown in Table 3. 
Table 2. The $\mathrm{L}_{25}(6)^{5}$ Taguchi design matrix for determination of curcumin.

\begin{tabular}{|c|c|c|c|c|c|c|c|}
\hline $\begin{array}{l}\text { Exp. } \mathrm{pH} \\
\text { no }\end{array}$ & $\begin{array}{c}\text { Amount of } \\
\text { the } \\
\text { extraction } \\
\text { solvent } \\
\text { (mg) }\end{array}$ & $\begin{array}{l}\text { Volume } \\
\text { of } \\
\text { disperser } \\
\text { solvent } \\
(\mu \mathrm{l})\end{array}$ & $\begin{array}{c}\text { Salt } \\
\text { effect } \\
\left(\mathrm{mol} \mathrm{L}^{-1}\right)\end{array}$ & $\begin{array}{l}\text { Sonic } \\
\text { ation } \\
\text { time } \\
\text { (min) }\end{array}$ & $\begin{array}{c}\text { Centr } \\
\text { ifuge } \\
\text { time } \\
\text { (min) }\end{array}$ & $\begin{array}{l}\text { Absor } \\
\text { ption }\end{array}$ & $S / N$ \\
\hline 1.0 & 21 & 100 & 0.00 & 0.0 & 2 & 0.063 & -24.0132 \\
\hline 1.0 & 31 & 300 & 0.03 & 0.5 & 5 & 0.326 & -9.736 \\
\hline 1.0 & 41 & 400 & 0.05 & 1.0 & 10 & 0.315 & -10.034 \\
\hline 1.0 & 51 & 500 & 0.06 & 1.5 & 15 & 0.299 & -10.486 \\
\hline 1.0 & 61 & 600 & 0.08 & 2.0 & 20 & 0.288 & -10.812 \\
\hline 1.5 & 31 & 400 & 0.00 & 2.0 & 15 & 0.301 & -10.429 \\
\hline 1.5 & 41 & 500 & 0.03 & 0.0 & 20 & 0.353 & -9.044 \\
\hline 1.5 & 51 & 600 & 0.05 & 0.5 & 2 & 0.349 & -9.143 \\
\hline 1.5 & 61 & 100 & 0.06 & 1.0 & 5 & 0.084 & -21.514 \\
\hline 1.5 & 21 & 300 & 0.08 & 1.5 & 10 & 0.337 & -9.447 \\
\hline 2.0 & 41 & 600 & 0 & 1.5 & 5 & 0.338 & -9.421 \\
\hline 2.0 & 51 & 100 & 0.03 & 2.0 & 10 & 0.143 & -16.893 \\
\hline 2.0 & 61 & 300 & 0.05 & 0.0 & 15 & 0.161 & -15.863 \\
\hline 2.0 & 21 & 400 & 0.06 & 0.5 & 20 & 0.304 & -10.342 \\
\hline 2.0 & 31 & 500 & 0.08 & 1.0 & 2 & 0.271 & -11.340 \\
\hline 3.0 & 51 & 300 & 0.00 & 1.0 & 20 & 0.204 & -13.807 \\
\hline 3.0 & 61 & 400 & 0.03 & 1.5 & 2 & 0.199 & -14.023 \\
\hline 3.0 & 21 & 500 & 0.05 & 2.0 & 5 & 0.236 & -12.542 \\
\hline 3.0 & 31 & 600 & 0.06 & 0.0 & 10 & 0.255 & -11.869 \\
\hline 3.0 & 41 & 100 & 0.08 & 0.5 & 15 & 0.045 & -26.936 \\
\hline 4.0 & 61 & 500 & 0.00 & 0.5 & 10 & 0.266 & -11.502 \\
\hline 4.0 & 21 & 600 & 0.03 & 1.0 & 15 & 0.395 & -8.068 \\
\hline 4.0 & 31 & 100 & 0.05 & 1.5 & 20 & 0.067 & -23.478 \\
\hline 4.0 & 41 & 300 & 0.06 & 2.0 & 2 & 0.219 & -13.191 \\
\hline 4.0 & 51 & 400 & 0.08 & 0.0 & 5 & 0.236 & -12.542 \\
\hline
\end{tabular}

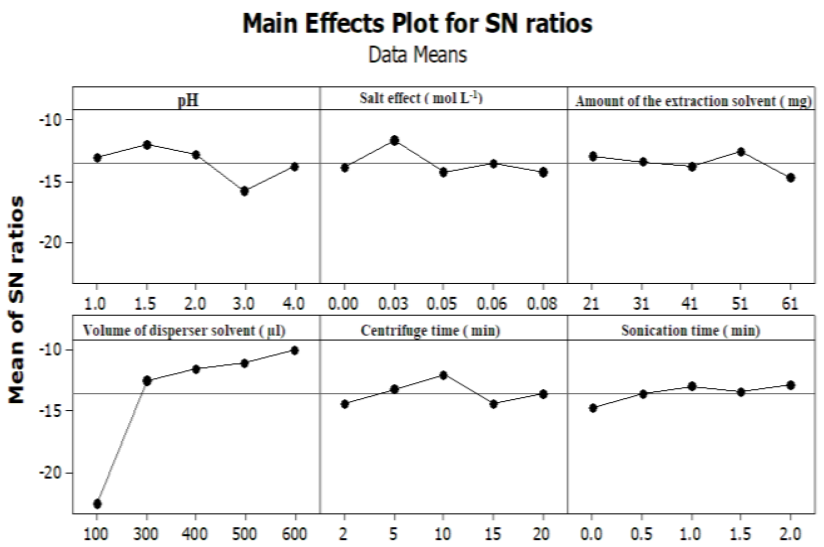

Signal-to-noise: Larger is better

Fig. 1. Main effects plot for extraction of curcumin.

\section{Effect of $p H$}

The $\mathrm{pH}$ of the solution plays a key role on extraction of analytes. According to Taguchi design, the effect of $\mathrm{pH}$ in the range of 1.0-4.0 (adjusting by $\mathrm{HCl}$ or $\mathrm{NaOH}$ ) on curcumin extraction was studied.
Table 3. ANOVA of the extraction of curcumin.

\begin{tabular}{llllll}
\hline Factor & Dof & $\begin{array}{l}\text { Sum of } \\
\text { Sqrs. }\end{array}$ & Variance & $\begin{array}{l}\text { F } \\
\text { ratio }\end{array}$ & $\begin{array}{l}\text { Percent } \\
(\%)\end{array}$ \\
\hline $\mathrm{pH}$ & 4 & 0.02531 & 0.0253 & 5.43 & 10.60 \\
\hline Salt effect & 4 & 0.01081 & 0.0108 & 2.32 & 4.53 \\
\hline $\begin{array}{l}\text { Amount of the } \\
\text { extraction solvent }\end{array}$ & 4 & 0.01294 & 0.0129 & 2.77 & 5.42 \\
\hline $\begin{array}{l}\text { Volume of } \\
\text { disperser solvent }\end{array}$ & 4 & 0.17874 & 0.1787 & 38.31 & 74.85 \\
\hline $\begin{array}{l}\text { Sonication time } \\
\text { Other/ error }\end{array}$ & 4 & 0.00629 & 0.0062 & 1.35 & 2.63 \\
\hline Total & 4 & 0.00466 & 0.0046 & & 1.95 \\
\hline
\end{tabular}

(a): degree of freedom

As shown in Fig. 1 and Fig. 2, and based on the ANOVA results, the effect of $\mathrm{pH}$ on the analytical signal of curcumin was significant and at the $\mathrm{pH}$ of 1.5 , the maximal signal was obtained. According to $\mathrm{pK}_{\mathrm{a}}$ reported for curcumin $\left(\mathrm{pK}_{\mathrm{a}}=8.52\right)[40]$ and $\operatorname{DeA}\left(\mathrm{pK}_{\mathrm{a}}=4.18\right)$ [41] (Fig. $\mathbf{3}(\mathbf{a}, \mathbf{b}))$, at lower $\mathrm{pH}$ values, they were neutral form and micelle formation is better. Looks influencing factor on extraction efficiency, is hydrogen bond between oxygen of band carboxylic acid group DeA with hydrogen of band hydroxyl group in curcumin structure. At higher $\mathrm{pH}$ values, aggregation of DeA and THF becomes weak for form reverse micelles and therefore recovery decreases. Therefore, the extraction efficiency is high. Hence, the $\mathrm{pH}$ of 1.5 was selected for the subsequent extractions.

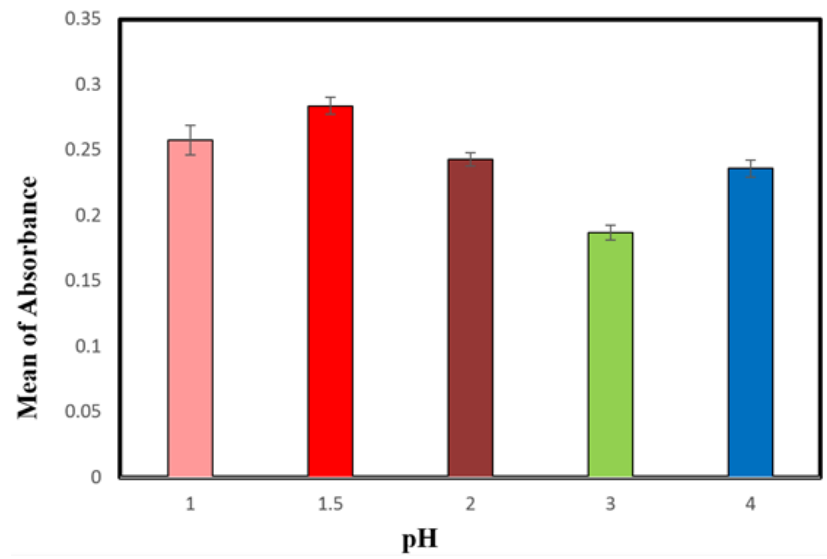

Fig. 2. Effect of the pH on the SM-UA-DSLLME. Extraction conditions: Total volume, $10.0 \mathrm{ml}$; concentration of curcumin, $0.2 \mathrm{mg} \mathrm{L}^{-1}$.<smiles>COc1cc(/C=C/C(=O)/C=C/c2ccc(O)c(O)c2)ccc1O</smiles><smiles>COc1cc(/C=C/C(=O)/C=C/c2ccc(O)c(OC)c2)ccc1O</smiles>

(a)<smiles>CCCCCCCCCC(=O)O</smiles>

(b)

Fig. 3. Molecular structure of Decanoic Acid (a) and Molecular structure of Curcumin (b). 


\section{Advanced Materials Letters https://aml.iaamonline.org}

\section{Salt effect}

The additions of salt into an aqueous solution can significantly improve the extraction of several analytes through salting out effect. In order to investigate the effect of salt addition on the extraction efficiency, the concentration of $\mathrm{KCl}$ was studied in the range of $0-0.08$ mol L-1 using the Taguchi method according to (Table 1). The extraction efficiency of curcumin was increased with increasing the $\mathrm{KCl}$ concentration up to $0.03 \mathrm{~mol} \mathrm{~L}^{-1}$ and thereafter decrease in the trend was observed. The results were shown in Fig. 1 and Fig. 4. The higher concentration of salt $\left(>0.03 \mathrm{~mol} \mathrm{~L}^{-1}\right)$ might reduce the diffusion rates of the analyte into the organic phase, that caused, reducing the rate of diffusion of the analytes into the extraction phase. Consequently, $0.03 \mathrm{~mol} \mathrm{~L}^{-1}$ of $\mathrm{KCl}$ was selected as the optimum concentration of salt. The ANOVA results showed that the value of effectiveness of salt effect was $4.53 \%$.

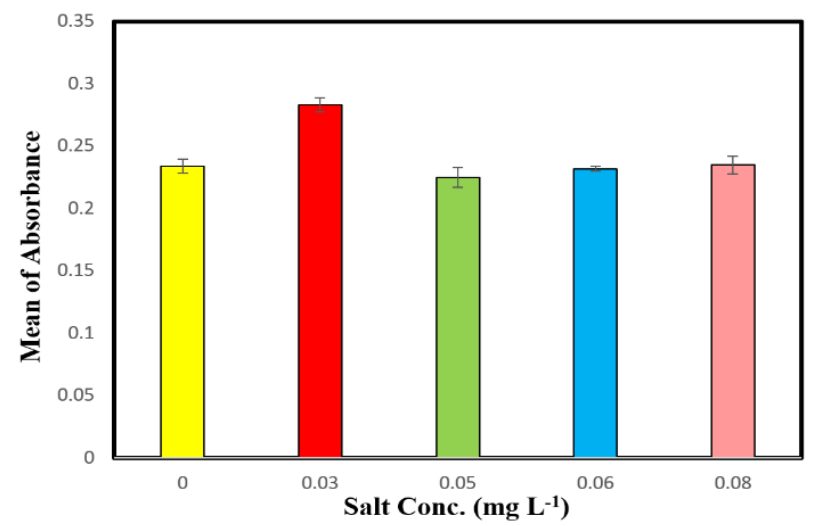

Fig. 4. Effect of the salt effect on the SM-UA-DSLLME. Extraction conditions: Total volume, $10.0 \mathrm{ml}$; concentration of curcumin, $0.2 \mathrm{mg} \mathrm{L}^{-1}$.

\section{Effect of extraction solvent amount}

To evaluate the effect of the extraction solvent amount, different volumes of DeA according to Taguchi design in the range of 21-61 mg were examined based on Table 1 . The results were shown in Fig. 1 and Fig. 5. The results showed that the amount of analyte extraction efficiency and its adsorption increases by increasing the amount of DeA. It can be seen that $51 \mathrm{mg}$ of DeA was adequate for quantitative extraction of curcumin. Therefore, $51 \mathrm{mg}$ of DeA was chosen as the optimum extracting solvent volume. The ANOVA results showed that the value of effectiveness of extracting solvent was $5.42 \%$.

\section{Effect of disperser solvent volume}

The effect of the volume of disperser solvent on extraction efficiency was studied in the range of $100-600 \mu \mathrm{L}$ according to Table 1. The results were shown in Fig. 1 and Fig. 6. The extraction efficiency of curcumin was increased with increasing the THF volume up to $600 \mu \mathrm{L}$ also in lower volumes, due to deficiency the disperser, the aggregation process is not complete.

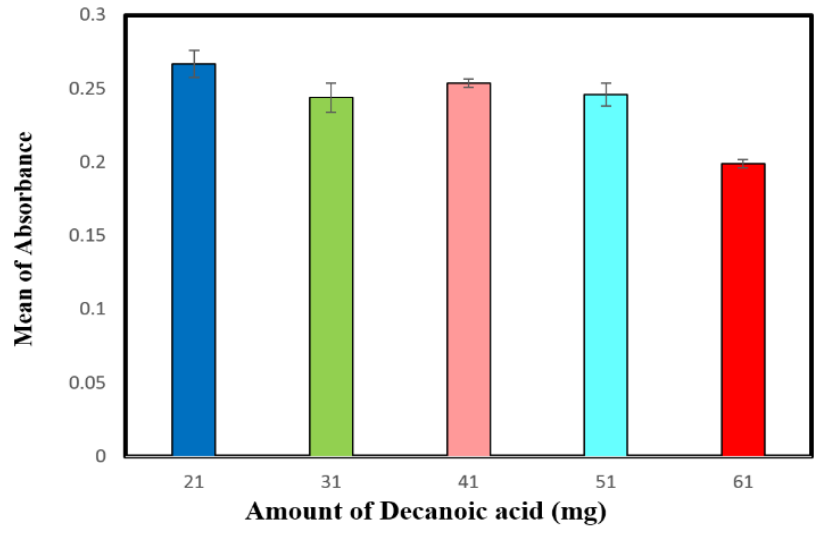

Fig. 5. Effect of the amount of extraction solvent on the SM-UADSLLME. Extraction conditions: Total volume, $10.0 \mathrm{ml}$; concentration of curcumin, $0.2 \mathrm{mg} \mathrm{L}^{-1}$

Based on the ANOVA results, the effect of disperser solvent volume on the determination of curcunin was significant and at the volume of 600 , the highest signal was obtained. Hence, the volume of $600 \mu \mathrm{L}$ was chosen for the subsequent extractions.

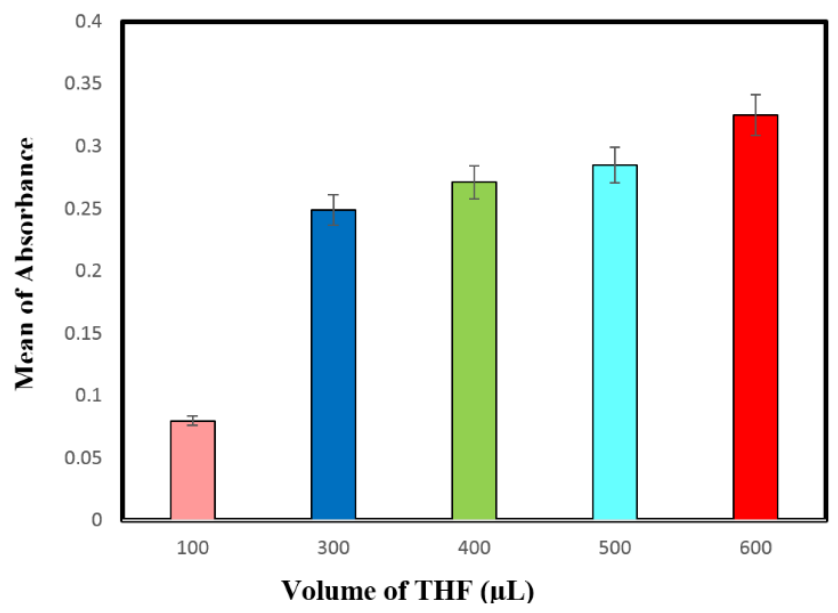

Fig. 6. Effect of the volume of disperser solvent on the SM-UA-DSLLME. Extraction conditions: Total volume, $10.0 \mathrm{ml}$; concentration of curcumin, $0.2 \mathrm{mg} \mathrm{L}^{-1}$.

\section{Effect of the sonication time}

The effect of the sonication time on extraction efficiency, was studied in the range of 0-2 min based on Table 1 . The results were shown in Fig. 1 and Fig. 7. Ultrasonic process accelerate the formation of a fine cloudy dispersive mixture and investigated its influence on extraction performances was examined. The results showed that the extraction efficiency is increased by increasing the ultrasonic time up to $1.0 \mathrm{~min}$ and then only slightly changed when the ultrasonic time was more than $1.0 \mathrm{~min}$. Consequently, 1.0 min was selected as the sonication time. The ANOVA results showed that the percentage contribution of sonication time was $2.63 \%$. 


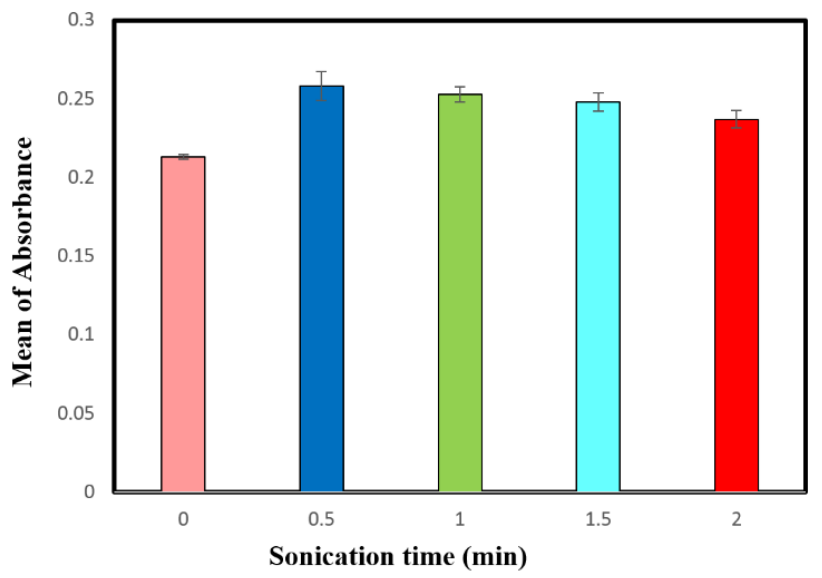

Fig. 7. Effect of the sonication time on the SM-UA-DSLLME. Extraction conditions: Total volume, $10.0 \mathrm{ml}$; concentration of curcumin, $0.2 \mathrm{mg} \mathrm{L}^{-1}$.

\section{Effect of the centrifuge time}

The effect of centrifuge time on the extraction efficiency was examined in the range of 2-20 min under Taguchi design according to Table 1. The results shown in Fig. 1 and Fig. 8, that indicate the maximal extraction efficiency was obtained in $10 \mathrm{~min}$ of centrifuges. At less than $10 \mathrm{~min}$, the two-phase separation is not performed completely and at more than $10 \mathrm{~min}$, there is a possibility to returne to the aqueous phase, likely. Therefore, $10 \mathrm{~min}$ of centrifuge was chosen as the optimum centrifuge time.

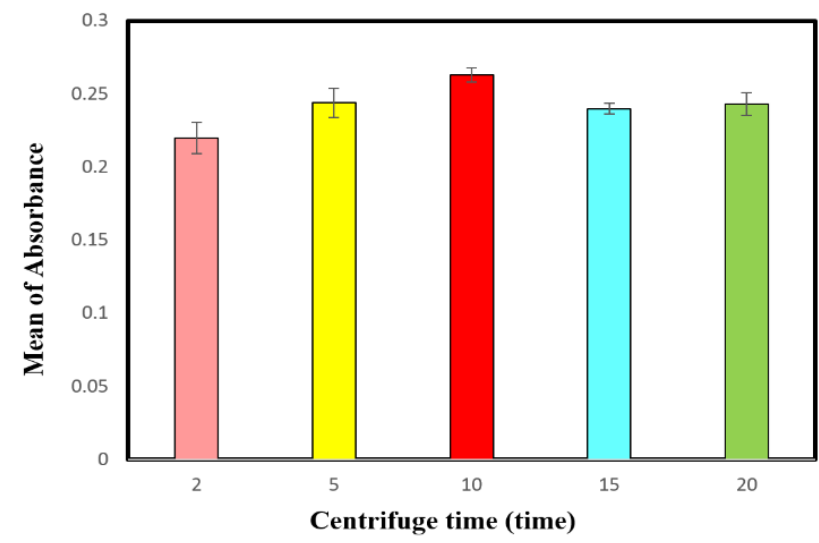

Fig. 8. Effect of the centrifuge time on the SM-UA-DSLLME. Extraction conditions: Total volume, $10.0 \mathrm{ml}$; concentration of curcumin, $0.2 \mathrm{mg} \mathrm{L}^{-1}$.

\section{Analytical figures of merits}

Under the optimal conditions obtained above, the analytical performance of the proposed method was investigated. The results obtained from Fig. 9, indicate the existence of two linear ranges of $0.01-0.40$ and $0.40-3.50 \mathrm{mg} \mathrm{L}^{-1}\left(\mathrm{R}^{2}=\right.$ 0.9922 and 0.9799 ), respectively. The limits of detection (LOD) calculated according to the equation $3 \mathrm{~s} / \mathrm{m}$, where $\mathrm{s}$ and $\mathrm{m}$ are the standard deviation of the blank signals of four replicates and the slope of the linear calibration graph, was found to be $5.2 \mu \mathrm{g} \mathrm{L}^{-1}$. The relative standard deviations (RSD \%) for eight replicate measurements of $0.2 \mathrm{mgL}^{-1}$ of curcumin was $2.47 \%$. The preconcentration factor $(\mathrm{PF})$ that define as ratio of the initial aqueous volume $(10.00 \mathrm{~mL})$ to the final volume $(200.00 \mu \mathrm{L})$ and under consideration extraction recovery was obtained 46. Finally, the enrichment factors based on the slope ratio of calibration curves with and without preconcentration, were obtained 478.48 and 118.80 for two linear ranges $0.01-0.40$ and 0.40 3.50 , respectively. The recovery of the method was about $92 \%$. A comparison between the results of this study and other extraction methods used for the extraction and preconcentration of curcumin is given in Table 4. The proposed procedure has good enrichment and preconcentration factors, low LOD and good precision in comparing the other methods.
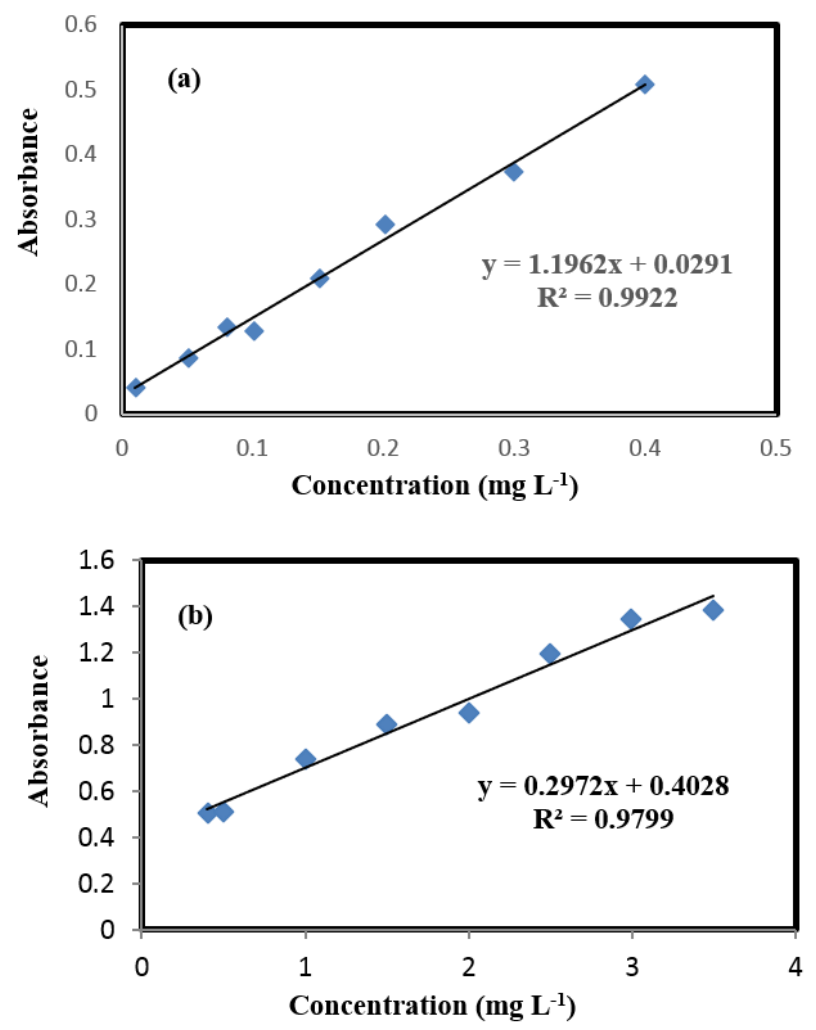

Fig. 9. Calibration graph of curcumin of two linear ranges of 0.01-0.40 and $0.40-3.50 \mathrm{mg} \mathrm{L}^{-1}$ under optimum conditions.

\section{Interference study}

The efficiency of the suggested method on the determination of curcumin in the presence of various cations, anions and dyes was examined. For this purpose, a solution of $0.2 \mathrm{mg} \mathrm{L}^{-1}$ of curcumin containing various amounts of interfering species was treated according to the optimized procedure. The tolerance limit was defined as the maximum concentration of foreign species producing an error of less than or equal to $\pm 5 \%$ in curcumin determination. As can be seen from Table 5, most of the cations and anions examined has no significant effect on the extraction of analytes and many of them are tolerated at high concentration levels. 
Table 4. Comparison of the proposed method with other reported methods for determination of curcumin.

\begin{tabular}{|c|c|c|c|c|c|c|c|}
\hline Method & $\mathrm{pH}$ & $\begin{array}{c}\mathrm{LR}^{\mathrm{a}} \\
\left(\mathrm{mg} \mathrm{L}^{-1}\right)\end{array}$ & $\begin{array}{l}D^{b} \\
(\mu g \\
\left.L^{-1}\right)\end{array}$ & $\begin{array}{c}\text { RSD } \\
(\%)\end{array}$ & $\mathrm{PF}^{\mathrm{c}}$ & $\begin{array}{c}\mathrm{Re} \\
\text { covery } \\
(\%)\end{array}$ & Ref. \\
\hline $\begin{array}{l}\text { CCT-CPE- } \\
\text { HPLC }\end{array}$ & 4.5 & $0.22-100$ & 66 & 2.7 & 9.5 & - & 42 \\
\hline UA-IL-DLLME & 3 & $0.0-5.0$ & 0.51 & 4.3 & 167 & 95 & 13 \\
\hline DLLME-UV/VIS & 4 & $0.01-2.0$ & 23 & 2.31 & 66.67 & 91.76 & 43 \\
\hline $\begin{array}{l}\text { DLLME-SFO- } \\
\text { HPLC }\end{array}$ & 3 & $5-1000$ & 1.2 & 8.0 & 25.3 & 95.5 & 44 \\
\hline SFDME & 3.5 & $23-2500$ & 2 & 2.72 & 10 & - & 45 \\
\hline DLLME-HPLC & - & $0.05-100$ & 5 & 2.87 & - & 90 & 12 \\
\hline VA-DES-ELLME & 4 & $9-920$ & 2.86 & 1.8 & 12.5 & 97 & 4 \\
\hline \multirow[t]{2}{*}{ SM-UA-DSLLME } & 1.5 & $0.01-0.40$ & 5.2 & 2.47 & 46 & 92 & \multirow{2}{*}{$\begin{array}{l}\text { This } \\
\text { study }\end{array}$} \\
\hline & & $0.40-3.50$ & & & & & \\
\hline
\end{tabular}

a: Linear range

b: Detection limit

c: Preconcentration factor

CCT-CPE:Cold column trapping-cloud point extraction

UA-IL-DLLME: Ultrasound-assisted ionic liquid-dispersive liquid-

liquid microextraction method

DLLME: Dispersive liquid-liquid microextraction.

DLLME-SFO: Dispersive liquid-liquid microextraction method based on solidification of floating organic droplet

SFDME: Solidification of floating drop microextraction

VA-DES-ELLME: Vortex assisted deep eutectic solvent-emulsification liquid-liquid micro-extraction

\section{Application to water and tablet samples}

To demonstrate the performance of the present method, was tested for the determination of curcumin in real samples with complex matrices, water and tablet samples by standard addition method. The curcumin were extracted and preconcentrated using the proposed method under the optimal conditions from the complex matrices.
Table 5. Tolerance limit of diverse species on the determination of $0.2 \mathrm{mg}$ $\mathrm{L}^{-1}$ curcumin.

\begin{tabular}{lc}
\hline Foreign ion/dye & $\begin{array}{c}\text { Tolerable limits of } \\
\text { interferences }\left(\mathbf{m g ~ L}^{-1}\right)\end{array}$ \\
\hline $\mathrm{SO}_{4}{ }^{2-}, \mathrm{NO}_{3}{ }^{-}$ & 500.0 \\
$\mathrm{PO}_{4}{ }^{3-}, \mathrm{Ca}^{2+}$ & 100.0 \\
$\mathrm{Cd}^{2+}, \mathrm{Zn}^{2+}, \mathrm{Mg}^{2+}, \mathrm{Na}^{+}$ & 500.0 \\
$\mathrm{Co}^{2+}$ & 250.0 \\
$\mathrm{Ni}^{2+}$ & 200.0 \\
$\mathrm{Fe}^{3+}, \mathrm{Cu}^{2+}$ & 10.0 \\
$\mathrm{Sunset}^{2+}$ yellow, Auramin O, & \\
Brilliant blue, Eosin B, Violet & 0.2 \\
covasol, Glucose, Sucrose & \\
\hline
\end{tabular}

Sample preparation for real samples was performed according to Section 2.4 Two types of water samples (tap water and sewage) were analyzed by spectrophotometer after SM-UA-DSLLME procedures. The results illustrated in Table 6, demonstrated that the recoveries of added curcumin are good (95.5-107 \%), indicating that the matrices of the samples type examined had no significant efficacy on the determination of curcumin.

The effectiveness of the SM-UA-DSLLME method for determination of curcumin was evaluated by analyzing tablet products that was obtained from the Dineh company (Tehran, Iran). Finally, the recoveries for curcumin from tablet were determined by adding $0.05,0.10,0.15,0.20 \mathrm{mg}$ $\mathrm{L}^{-1}$ standards to the prepared sample solution before SMUA-DSLLME, and the results are provided in Table 6. These results demonstrate the validity of the proposed extraction method.

Table 6. Determination of curcumin and calculated recoveries in real water and tablet samples.

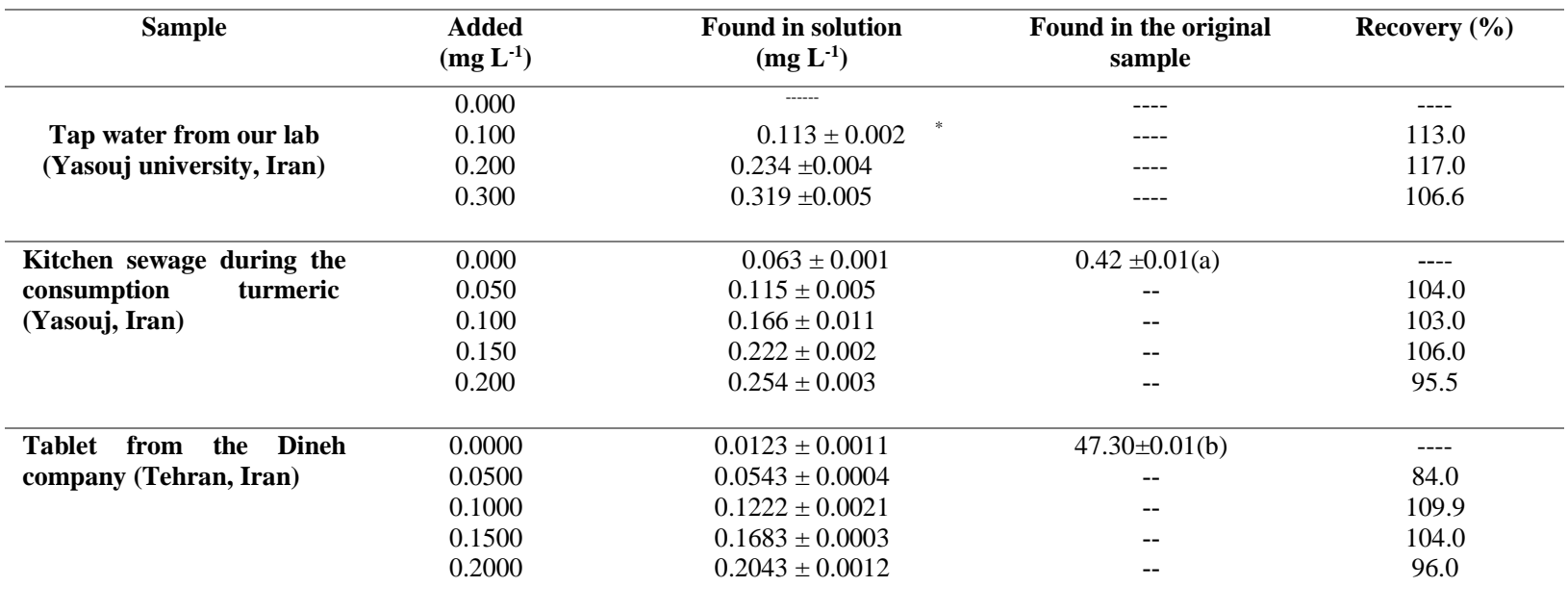

Mean \pm standard deviation.

(a) $\mathrm{mg} \mathrm{L}^{-1}$

(b) mg per one tablet 


\section{Advanced Materials Letters https://aml.iaamonline.org}

\section{Conclusion}

The study successfully applied the Taguchi method to determine optimal UA-SM-DSLLME for the extraction and preconcentration of curcumin in tablet, sewage, and water samples. The results of ANOVA showed that volume of disperser solvent has significant effect on the extraction of curcumin. The proposed method has some advantages such as inexpensive, low consumption and easy to operate with high preconcentration factor, low LOD, good precision, environmentally friendly, rapid, sensitive and requires minimal use of toxic organic solvents. This method can be successfully applied to the preconcentration and determination of curcumin in tablet, sewage and water samples.

Also, the obtained results show that the application of this method can be successful for the analysis of curcumin in human blood serum, urine samples, biological samples, food and herbal samples. This method can be coupled with other detection techniques, such as high-performance liquid chromatography (HPLC) for the determination of ultratraces of curcumin.

\section{Acknowledgements}

The authors gratefully acknowledge the support of Yasouj University for this study.

\section{Keywords}

Curcumin; Supramolecular solvent; Microexraction; Taguchi design method; Tablet sample

\section{Received: xx Month 20xx \\ Revised: $x x$ Month 20xx \\ Accepted: xx Month 20xx}

\section{References}

1. Mahmood, K.; Zia, K. M.; Zuber, M.; Salman, M.; Anjum, M. N.; Int. J. Biol. Macromol., 2015, 81, 877.

2. Gong, C.Y.; Wu, Q.; Wang, Y.; Zhang, D.; Luo, F.; Zhao, X.; Wei, Y.; Qian, Z.; Biomaterials, 2013, 34, 6377-6387.

3. Tønnesen, H. H.; Másson, M.; Loftsson, T.; Int. J. Pharm., 2002 244, 127-135.

4. Aydin, F.; Yilmaz, E.; Soylak, M.; Food Chem., 2018, 243, 442-447.

5. Euterpio, M. A.; Cavaliere, C.; Capriotti, A. L.; Crescenzi, C.; Anal. Bioanal. Chem., 2011, 401, 2977.

6. Lopez-Fernandez, O.; Rial-Otero, R.; Cid, A.; Simal-Gandara, J.; Food Chem., 2014, 145, 1002-1010.

7. Hyötyläinen, T.; Anal. Bioanal. Chem., 2009, 394, 743-758.

8. Jayaprakasha, G. K.; Rao, L. J. M.; Sakariah, K. K.; J. Agric. Food Chem., 2002, 50, 3668-3672.

9. Hashemi, P.; Naderlou, M.; Safdarian, M.; Ghiasvand, A. R.; Anal. Chem. Lett., 2013, 3, 92-101.

10. Rezaee, M.; Assadi, Y.; Milani, M. R.; Aghaee, E.; Ahmadi, F.; Berijani, S.; J. Chromatogr. A, 2006, 1116, 1-9.

11. Hosseini, M.; Heydari, R.; Alimoradi, M.; Talanta, 2014, 130,171176.

12. Afkhami, A.; Pirdadeh-Beiranvand, M.; Madrakian, T.; Anal. Bioanal. Chem. Res., 2017, 4, 1-10.

13. Unsal, Y. E.; Tuzen, M.; Soylak, M.; J. AOAC Int., 2019, 102, 217.

14. Rocha, B. A.; de Oliveira, S. R.; da Silva, R. M.; Barcelos, G. R. M.; de Oliveira, A. R. M.; Barbosa, Jr. F.; Microchem J., 2019, 147, 207214.

15. Jing, L.; Meng-Meng, W.; Qiang, W.; Hai-Pu, L.; Zhao-Guang, Y.; Chinese J. Anal. Chem., 2018, 46, e1817-e1825.
16. Shokrollahi, A.; Ebrahimi, F.; J. AOAC Int., 2017, 100, 1861.

17. Senaa, L. C. S.; Matosb, H. R.; Dóreac, H. S.; Pimenteld, M. F.; de Santanae, D. C. A. S.; de Santanae, F. J. M.; Toxicol., 2015, 376 , 102-112.

18. Sanagi, M. M.; Abbas, H. H.; Wan Ibrahim, W. A.; Aboul-Enien, H Y.; Food Chem., 2012, 133, 557.

19. Shokrollahi, A.; Behrooj Pili, H.; Hemmati Doust, K.; Art., 2017, 72 , 617-623.

20. Altunay, N.; Unal, Y.; Elik, A.; Food Addit. Contam. Part A, 2020 37,1944 .

21. Menghwar, P.; Yilmaz, E.; Soylak, M.; Sep. Sci. Technol., 2018, 53 , 2612-2621

22. Ballesteros-Gómez, A.; Sicilia, M. D.; Rubio, S.; Anal. Chim. Acta 2010, 677, 108-130.

23. Costi, E. M.; Sicilia, M. D.; Rubio, S.; J. Chromatogr. A, 2010, 1217 , $1447-1454$

24. Luque, N.; Rubio, S.; Pérez-Bendito, D.; Anal. Chim. Acta, 2007, 584,181

25. López-Jiménez, F. J.; Rubio, S.; Pérez-Bendito, D.; Food Chem. 2010, 121, 763-769.

26. Ruiz, F. J.; Rubio, S.; Pérez-Bendito, D.; J. Chromatogr. A, 2007, 1163, 269-276.

27. Ruiz, F. J.; Rubio, S.; Pe '́rez-Bendito, D.; Anal. Chem., 2007, 79 , 7473-7484.

28. Berijani, S.; Assadi, Y.; Anbia, M.; Milani Hosseini, M-R.; Aghaee, E.; J. Chromatogr. A, 2006, 1123, 1-9.

29. Ravelo-Pérez, L. M.; Hernández-Borges, J.; Asensio-Ramos, M.; Rodríguez- Delgado, M. Á.; J. Chromatogr. A, 2009, 1216, 73367345 .

30. Cortada, C.; Vidal, L.; Pastor, R.; Santiago, N.; Canals, A.; Anal. Chim. Acta, 2009, 649, 218-21.

31. Afrasiabi, H.; A, Khayati, G. R.; Ehteshamzadeh, M.; Int. J. Eng., 2014, 27, 1423-1430.

32. Ballesteros-Gómez, A.; Ruiz, F. J.; Rubio, S.; Pe 'rez-Bendito, D.; Anal. Chim. Acta, 2007, 603, 51-59.

33. Rezaee, M.; Yamini, Y.; Khanchi, A.; Faraji, M.; Saleh, A.; $J$ Hazard. Mater., 2010, 178, 766-770.

34. Wu, Ch. X.; Wu, Q. H.; Wang, Ch.; Wang, Z.; Chin. Chem. Lett., 2011, 22, 473-476.

35. Leong, M. I.; Huang, H.; J. Chromatogr. A, 2008, 1211, 8-12.

36. Wang, Y.; Zhang, J.; Zhao, B.; Du, X.; Ma, J.; Li, J.; Biol. Trace Elem. Res.; 2011, 144, 1381-1393.

37. Atil, H.; Unver, Y.; J. Biol. Sci., 2000, 3, 1538.

38. Artola, A.; Balaguer, M. D.; Rigola, M.; Water Res., 1997, 31, $997-$ 1004

39. Petersen, J. N.; Drying Technol., 1986, 4, 319-330.

40. Bernabé-Pineda, M.; Ramírez-Silva, M. T.; Romero-Romo, M.; González- Vergara, E.; Rojas-Hernández, A.; Spectrochim. Acta Part A., 2004, 60, 109-1097.

41. Wellen, B. A.; Lach, E. A.; Allen, H. C.; Phys. Chem. Chem. Phys, 2017, 19, 26445.

42. Rahimi, M.; Hashemi, P.; Nazari, F.; Anal. Chim. Acta, 2017, 826, $35-42$.

43. Asfaram, A.; Ghaedi, M.; Alipanahpour, E.; Agarwal, S.; Gupta, V. K.; Food Anal. Methods, 2016, 9, 1274-1283.

44. Hashemi, P.; Naderlou, M.; Safdarian, M.; Ghiasvand, A. R.; Anal. Chem. Lett., 2013, 3, 92-101.

45. Safdarian, M.; Hashemi, P.; Naderlou, M.; J. Chromatogr. A, 2012 1244, 14-19. 